TRADUÇÃO 



\title{
GÊNEROS DO ENSINO: UMA ABORDAGEM BAKHTINIANA ${ }^{* * *}$
}

\section{TEACHING GENRES: A BAKHTINIAN APPROACH}

\author{
Elsie Rockwell ${ }^{*}$ \\ Tradução de Clécio Bunzen e Regina Vieira**
}

\section{RESUMO}

Este artigo enfatiza a natureza cultural e histórica do ensino. Com base na teoria dos gêneros do discurso de Bakhtin, aborda-se a interação em sala de aula como um gênero secundário que reflete a história do ensino em cada localidade. A análise de uma aula observada em uma comunidade rural no México mostra como gêneros de origens diversas comunicam diferentes tipos de conhecimentos, quando imbricados na conversação em curso na sala de aula. Palavras-chave: gêneros do ensino, interação em sala de aula, história do ensino.

\section{ABSTRACT}

This article stresses the cultural/historical nature of teaching. Drawing on Bakhtin's theory of speech genres, it approaches classroom discourse as a composite genre that reflects the history of teaching in each locality. The analysis of a lesson observed in a rural school in Mexico shows how genres drawn from a variety of sources convey different sorts of knowledge as they are woven into ongoing classroom conversation.

Keywords: teaching genres, classroom discourse, history of teaching.

Como antropólogos, aprendemos a ver a educação como um processo cultural. Entretanto, o estudo das especificidades das práticas de ensino é bastante recente e tem se oposto à tendência de se enfatizar as similaridades no ensino entre

\footnotetext{
* Centro de Investigación y de Estudios Avanzados do Instituto Politécnico Nacional (IPN), México. rockwell@cinvestav.mx

** UFSP, São Paulo (SP), Brasil. clecio.bunzen@gmail.com; IFPE, Caruaru (PE). anaregina@recife. ifpe.edu.br;

Agradecemos à professora Elsie Rockwell, pela autorização da tradução e pela atenção e apoio dispensados. Aos professores Angela Kleiman (UNICAMP), Normanda Beserra (UFPE) e Mizael Nascimento (UFRPE) pela leitura e pelas pertinentes sugestões.

*** Artigo reproduzido da revista Antbropology \& Education Quarterly, volume 31 (3), pp. 260-282, 2000, com a permissão da American Anthropological Association. São proibidas a venda e outras reproduções.
} 
contextos culturais ${ }^{1}$. Meu interesse em gêneros do discurso é voltado para a tarefa emergente de mapear a variação cultural e a mudança histórica nas práticas de ensino. Por isso, afirmo que os professores não se baseiam apenas nos recursos pedagógicos diversos de suas próprias culturas de formação e de local de trabalho, mas também nos recursos culturais locais e regionais mais arraigados. Para explicar diferenças entre professores, precisamos desenvolver conceitos que capturem a especificidade cultural da interação em sala de aula e, que, ao mesmo tempo, sirvam para comparar esse tipo de interação entre diferentes culturas e traçar a sua trajetória no tempo.

Neste sentido, considero útil o conceito de gêneros do ensino, baseado no trabalho de Bakhtin. Embora o trabalho do estudioso soviético inspire muito a pesquisa sobre a sala de aula ${ }^{2}$, a atenção geralmente se volta para suas ideias fundamentais de dialogismo e beteroglossia. Essas ferramentas permitem que os pesquisadores explorem o nexo existente entre o significado situado dos enunciados e os significados advindos de múltiplos enunciados prévios e paralelos, para refletir sobre as muitas vozes presentes nas salas de aulas, nas trocas entre participantes e na própria fala de cada participante $^{3}$. As ideias de Bakhtin sobre gênero ou forma genérica, por outro lado, recebem menos atenção nas análises da interação em sala de aula. Sua conceitualização estende a noção tradicional de gênero, em geral limitada prioritariamente a certos tipos de textos (ensaios, romances, epopeia etc.), a todos os enunciados escritos e falados ${ }^{4}$; assim como enfatiza a formação histórico-cultural de gêneros complexos usados em esferas de atividades particulares. No texto a seguir, desenvolvo essa perspectiva teórica em relação ao ensino e, depois, ilustro a abordagem com um exemplo retirado de minha pesquisa etnográfica na região central do México.

\section{O GÊNERO DA PESQUISA EDUCACIONAL}

O conceito de gênero encontra-se presente na teoria educacional já há algum tempo e geralmente designa as formas convencionadas de textos escritos ensinados

1 Seguindo a linha dos Spindlers, alguns antropólogos descrevem a dimensão cultural do ensino, muito embora a maioria das pesquisas enfatize as similaridades. Ver a revisão da literatura sobre o tema em Anderson-Levitt, 2002.

2 Os trabalhos que usam as ideias de Bakhtin para estudar a sala de aula incluem: Hicks (1996); Kozulin (1996); Lemke (1990), Maybin (1994), Mercado (1994), Mercer (1995); O’Connor e Michaels (1996); Schneuwly (1994); e, finalmente, Wertsch (1991).

3 Briggs (1988, p. 254-256) discute esses dois tipos de dialogismo - externo e interno - no discurso. Um conceito correspondente de cultura, necessário a essa abordagem, pode ser encontrado em De Certeau (1994) e em Mannheim e Tedlock (1995).

4 Bakhtin usa o "enunciado" como a unidade básica de análise em qualquer "corrente de comunicação", mas insere aí desde a curta "réplica de uma única palavra" do diálogo cotidiano até o romance. 
ou usados nas escolas. A pedagogia do gênero, iniciada na Austrália, atraiu a nossa atenção para as regras do discurso - particularmente do discurso escrito - implícitas no aprendizado de cada disciplina escolar e nos métodos para apresentar explicitamente tais regras (CAZDEN, 1996; CHRISTIE, 1987; FREEDMAN e MEDWAY, 1994; KRESS, 1997; LEMKE, 1990; RUSSEL e BAZERMAN, 1997). Utilizando um arcabouço conceitual diferente, Bronckart (1994) mostra que gênero é um conceito poderoso para articular um modelo vigotskiano de ensino, baseado na ideia de apropriação de instrumentos semióticos e no papel que esses instrumentos desempenham como mediadores da aprendizagem e do desenvolvimento.

O conceito de gênero também vem sendo usado para descrever a interação em sala de aula. No passado, os estudiosos inclinavam-se a identificar um gênero, geralmente a aula (lesson), como característico do ensino. Por exemplo, Wertsch focaliza "um único gênero do discurso, que emerge e luta para desempenhar um papel dominante em um cenário sociocultural específico do ensino formal" (1991, p. 110). Considerar a aula como um único gênero evidencia a sua especificidade se comparada à fala em outros cenários, incluindo a conversação cotidiana.

Ao descrever aulas, a pesquisa centra-se frequentemente nos padrões interativos IRA ou IRF5, considerados modelos de fala na sala de aula (CAZDEN, 1988). Embora esse modelo tenha sido originalmente usado como uma estrutura analítica (MEHAN, 1979; SINCLAIR e COULTHARD, 1975), alguns estudiosos consideram-no "uma espécie de gênero" (LEMKE, 1990, p. 123) ou, de fato, o "gênero do discurso dominante" encontrado no ensino (WELLS, 1993, p. 15-29). ${ }^{6}$ Embora os padrões IRA/IRF pareçam permear quase todas as transcrições de sala de aula, a análise detalhada da estrutura de participação (O'CONNOR e MICHAELS, 1996), da simultaneidade e do ritmo (ERICKSON, 1996) e das estruturas de preferência (CANDELA, 1999) mostram que o modelo carece da sutileza que as análises da conversação e da prosódia emprestam à nossa compreensão da fala. Nessa direção, eu ainda argumentaria que os padrões IRA/F compreendem a interação na sala de aula como homogênea e, assim, não são úteis para descrever gêneros culturalmente específicos, usados em diferentes tradições escolares.

As pesquisas de sala de aula mais recentes produzem evidências crescentes da diversidade cultural no ensino. Esses estudos descrevem uma variedade de

\footnotetext{
5 IRA refere-se a "Iniciação, Resposta e Avaliação" (MEHAN, 1979); em IRF, o "F" significa Feedback ou Follow-up (WELLS, 1993). Erickson resume essa estrutura como uma "pergunta de informação-conhecida, iniciada pelo professor, seguida por uma resposta de um aluno, por seu turno, seguida de uma avaliação da resposta pelo professor" (1996: 31).

6 Embora Wells $(1993,33-34)$ reconheça a heterogeneidade, ele atribui a diversidade principalmente à escolha do registro pelo professor, mais do que à diversidade dos gêneros.
} 
padrões de fala-em-interação, muitos dos quais, de fato, gêneros, relacionados a diferentes estruturas de atividade e áreas de conteúdo. Por exemplo, Hicks (1996) e Mercer (1995, p. 22-23) revisam estudos que mostram o uso cotidiano da narrativa em salas de aulas em diferentes países. Outras evidências de heterogeneidade podem ser encontradas em estudos etnográficos que descrevem as características culturais do discurso, como, por exemplo, dos professores afro-americanos (FOSTER, 1995) e haitianos (BALLENGER, 1997), ou - seguindo uma linha teórica diferente - a dimensão discursiva da cultura capitalista, como transmitida em uma escola de ensino médio do Texas (FOLEY, 1990). Esses estudos - e muitos outros - sugerem a necessidade de se desenvolver um conceito de gêneros do ensino que possa distinguir os muitos gêneros orais usados para ensinar.

\section{REEXAMINANDO GÊNERO: AS PISTAS DOS ESTUDOS DO FOLCLORE}

O conceito de gênero usado atualmente vai muito mais além da referência às formas literárias escritas e até então associadas ao termo, para enriquecer o estudo dos recursos comunicativos orais e não literários. Enquanto os gêneros escritos são relativamente fáceis de ser identificados, os gêneros fundados na oralidade são de difícil delimitação. Como aponta Bronckart, "eles têm contornos imprecisos e permeáveis [...] e resistem à classificação" (1994, p. 378; tradução minha). Progressos significantes na compreensão de gêneros orais foram alcançados inicialmente na área do Folclore. Bauman abordou os gêneros orais como "tipos de enunciados convencionados que incorporam as características que organizam a performance" (1977, p. 25). Esse autor ajudou a ampliar a nossa visão para uma gama de gêneros possíveis em cada esfera ao alertar que "a atenção do investigador vai se voltar, primeiramente, para aqueles gêneros cuja performance é convencionada[...]. No entanto, o investigador deveria também estar atento àqueles gêneros cuja probabilidade de performance é mais baixa $[\ldots]$, mas que não causam surpresa alguma se entram em ação" (1977, p. 26).

O foco na poética da performance inaugurou uma nova abordagem dos modos culturais de fala. Em seu estudos sobre "Mexicano Verbal Art", realizado no Novo México, Briggs (1988, p. 10-18) reitera que a performance dos gêneros orais é moldada pela interação social. O pesquisador argumenta que as pessoas que apresentam um boa performance, de fato, "desenvolvem a competência de incorporar elementos textuais na interação em curso" $(1988$, p. 4), às vezes, até deliberadamente, tornando confusa a distinção entre performance e conversação. Esses insights têm a ver com 
o ensino. Por um lado, o ensino na sala de aula envolve uma performance; por outro, implica uma "longa conversação"(MAYBIN, 1994, p. 136; MERCER, 1995, p. 70). Observando a partir dessa perspectiva, a performance de gêneros orais de um professor pode se incorporar à conversação em curso na sala de aula e evidenciar o gap intertextual ${ }^{7}$ (BRIGGS e BAUMAN, 1992).

Os gêneros são culturalmente específicos. Embora possamos encontrar similaridades entre culturas, os gêneros (por exemplo, as piadas) desenvolvem marcas e pistas, nuances e regras de cada ambiente cultural. Assim, deve-se cuidar para não confundir gêneros com categorias que são propostas como universais, tais como os tipos textuais (narrativo, argumentativo), tipos de fala (tal como a fala exploratória), regras de cunho pragmático (tais como as máximas de relevância) ou estruturas de troca verbal (como o padrão IRF, por exemplo). Os termos utilizados para fazer referência a gêneros deveriam fazer sentido dentro da cultura local onde as características particulares de uma performance considerada aceitável são moldadas. Se esses termos não existirem, então deve ser encontrada outra evidência para fundamentar a relevância cultural atribuída ao padrão discursivo que pode ser identificado como um gênero.

Os gêneros também têm histórias. A recorrência de características similares no tempo cria um frame interpretativo relativamente estável. Ao usar um gênero oral, os falantes têm que satisfazer certas condições sociais (como, por exemplo, quem é legitimado para usar o gênero) e utilizar os frames discursivos específicos que envolvem entonação, marcadores de abertura e fechamento e características estilísticas (BRIGGS, 1988, p. 9). Assim, ambos, participantes e pesquisadores, podem compreender as instâncias particulares de uso da língua à luz das tradições genéricas de onde elas emergem (SWALES, 1990, p. 42-44). Tal codificação pode ocorrer independentemente de os gêneros receberem (ou não) uma denominação na metalinguagem local, porque os participantes oferecem respostas apropriadas a muitos modos convencionados de falar que possuem as propriedades de um gênero, mesmo quando não tenham sido ainda nomeados.

\footnotetext{
$7 \mathrm{O}$ termo gap intertextual remete à situação de produção de textos e, mais especificamente, ao processo de ligar enunciados particulares a um determinado modelo genérico que gera uma espécie de hiato ou distanciamento intertextual. Optamos por não traduzir a palavra gap, seguindo tradução anterior do termo para o português (cf. $\mathrm{KOCH}$, Ingedore et alli. Intertextualidade: diálogos possíveis. São Paulo: Cortez, 2007). [NT].
} 


\title{
O CONCEITO DE GÊNERO DE BAKHTIN
}

Para explorar a dimensão cultural e histórica dos gêneros discursivos, voltei-me para Bakhtin, uma tradição não tão distante daquela de Bauman. $\mathrm{O}$ conceito bakhtiniano de gênero é, por vezes, considerado de difícil tradução em termos analíticos. Sua abordagem sugere trajetórias diferentes daquelas utilizadas em métodos formais, tais como a semiótica social e a análise da conversação. Além disso, Bakhtin (1986, p. 60-61) trata a noção de gênero do discurso como uma categoria histórica, descartando, dessa forma, a possibilidade de se estabelecer uma tipologia completa e apontando mais exatamente para a crescente complexidade dos gêneros usados em determinadas esferas:

\begin{abstract}
Cada esfera de utilização da língua elabora seus tipos relativamente estáveis de enunciados, sendo isso que denominamos gêneros do discurso. A riqueza e a diversidade dos gêneros do discurso não têm limites, porque as diversas possibilidades da atividade humana são inesgotáveis, e cada esfera de atividade comporta um repertório de gêneros do discurso que se diferencia e se amplia à medida que a própria esfera desenvolve-se e torna-se mais complexa. Uma ênfase particular deveria ser dada à extrema beterogeneidade dos gêneros do discurso (orais e escritos) (1986, p.60).
\end{abstract}

Na visão de Bakhtin, todos os enunciados envolvem, usam e transformam os gêneros do discurso. Os gêneros não existem como segmentos de discurso real, mas, muito mais, como formas convencionadas de que os falantes se valem para produzir e interpretar enunciados. Esse processo não é totalmente deliberado: "usamos (os gêneros) com segurança e habilidade na prática e é possível que sequer suspeitemos de suas existências na teoria" (BAKHTIN, 1986, p. 78). Além disso, embora nem todos os falantes sejam igualmente adeptos ao uso das formas genéricas de uma dada esfera, eles de fato usam essas formas criativamente, combinando gêneros de várias esferas e reconfigurando-os no curso da interação de seus repertórios particulares e estilos individuais (BAKHTIN, 1986, p. 78). Bakhtin utiliza esse frame conceitual para analisar gêneros literários - particularmente os romances - em seus contextos culturais e históricos. Sua reflexão considera o romance como um gênero "complexo" ou "secundário", uma forma complexa particular que tende a incorporar muitos gêneros primários, tais como cartas, monólogos ou versos. Se abordarmos o ensino como Bakhtin abordou o romance - sem perdermos de vista as diferenças significantes entre essas duas formas -, seremos capazes de revelar algumas das forças culturais e históricas que influenciam o discurso de sala de aula. ${ }^{8}$ Ao explorar essa analogia, uma visão diferente dos gêneros do ensino começa a ser moldada. Vejo aí

8 Kozulin (1996) defende o uso de modelos literários para estudar processos educacionais. 
pelo menos quatro caminhos - os quais ilustrarei a seguir -, que partem da teoria de Bakhtin em direção a um conceito de gêneros do ensino.

Em primeiro lugar, podemos considerar o ensino como uma das esferas da atividade humana dentro das quais repertórios particulares de gêneros do discurso vêm sendo absorvidos, desenvolvidos e combinados para formar gêneros complexos ou secundários ${ }^{9}$ (BAKHTIN, 1986, p. 61). Cada gênero do ensino é o resultado de uma combinação particular de gêneros formada ao longo do tempo. Assim, os gêneros do ensino são múltiplos e mutantes. Bakhtin menciona alguns gêneros usados no ensino da forma como ele os conheceu, como, por exemplo, os diálogos de Sócrates, os Milagres do teatro medieval e os diálogos nos "encontros no mundo de além-túmulo" que se tornaram frequentes "no nível mais básico dos exercícios escolares" (1984, p. 136,142). ${ }^{10}$ Seguindo essa pista, podemos investigar como determinados professores incorporam e usam gêneros distintos.

Em segundo lugar, os diversos gêneros encontram-se inseridos nas conversações correntes na sala de aula. $\mathrm{O}$ ensino é inerentemente dialógico, no sentido bakhtiniano: uma resposta é constantemente requerida, aguardada, evocada, esperada. Até quando não existe uma resposta verbal imediata, o enunciado do professor solicita uma reação ou permanece à espera de outro momento quando novamente pode ser discutido, aceito ou sutilmente refutado pelos alunos. Algumas vezes, o professor responde suas próprias perguntas, ou a resposta do aluno é não verbal ou monossilábica. Entretanto, durante momentos de intensa participação, a natureza dialógica da interação professor-aluno é explícita: os enunciados sucedem-se e antecipam-se uns aos outros numa rápida sequência de turnos. Dentro dessa estrutura, ambos, professor e alunos, recorrem a uma variedade de recursos genéricos.

Em terceiro lugar, ao abordar os gêneros do ensino com base nessa perspectiva, o conteúdo importa tanto quanto a forma. Nos termos de Bakhtin, certas "categorias de pensamento" estão inseridas nas tradições genéricas. Essas categorias não são "ideias abstratas", mas, sim, "'ideias' concreto-sensoriais, espetacular-rituais vivenciáveis e representáveis na forma da própria vida, que se formaram e viveram ao longo de milênios" (BAKHTIN, 1984, p. 123). Nas práticas de sala de aula, gêneros específicos são usados para representar certos conteúdos, para sistematizar o conhecimento escolar e expressar experiências. Alguns deles podem derivar das

\footnotetext{
9 O termo "multigenred genres" no original foi traduzido por "gêneros secundários" [NT].

10 Bakhtin, na obra Problemas da Poética de Dostoiévski, comenta justamente que diversos tipos de comportamentos dos "mortos no reino de além-túmulo" (inferno carnavalizado) aparecem em algumas obras literárias. Ao fazer tal comentário, menciona brevemente que a situação-gênero "encontro no mundo de além-túmulo" serviu de imitação tanto na literatura como nos exercícios escolares na Rússia do século XVIII. [NT].
} 
representações escritas do conhecimento em diferentes épocas; outros correspondem às tradições orais.

Finalmente, os gêneros do ensino são heterogêneos e podem se diferenciar entre localidades (quantas forem definidas) e até mesmo dentro de algumas tradições. Retomando os vários termos de Bakhtin, podemos ver cada professor trabalhando em uma "atmosfera genérica" e baseando-se na "história dos gêneros", enquanto desenvolve a sua maneira particular de falar quando ensina. $\mathrm{O}$ ensino é influenciado, ainda, pelas "forças que moldam gêneros", incluindo aí as restrições de tempo, espaço e agrupamento, as tendências da formação do professor e os padrões culturais locais. Assim, a pesquisa pode buscar "tradições genéricas" específicas, em vez de assumir padrões ou cânones universais. A historicidade dos gêneros do ensino de hoje é baseada nas influências acumuladas que moldam gêneros. Dentro do espírito da poética histórica proposta por Bakhtin, "um gênero vive do presente, mas sempre recorda o seu passado" (1984, p. 106).

A identificação dos gêneros do ensino em salas de aula contemporâneas causa problemas para a pesquisa. Os gêneros nunca emergem em uma forma pura; eles vão sendo constantemente modificados dentro da co-construção da ação e do significado em curso na sala de aula. Nesse processo, porém, os diversos gêneros geralmente preservam certas características que lhes permitem ser reconhecidos pelos participantes. Um bom sinal é observar os nomes comuns que os participantes usam para se referir aos modos de falar (SWALES, 1990, p. 54-56). No entanto, os professores raramente dão nome aos gêneros no curso de sua fala. Falar sobre ensino, em si, já implica a existência de uma história refletida nos modos como pessoas habilitadas na área e pesquisadores descrevem, hoje, o discurso da sala de aula. Para não impor um modelo analítico arbitrário às descrições de professores particulares, é necessário perceber a historicidade das categorias que podem distinguir gêneros. Assim, devemos buscar evidências de codificação ou de adoção de certos gêneros dentro das culturas de ensino locais e não apenas assumir que eles estão presentes ou são relevantes. A tarefa é desenvolver um frame para estudar os gêneros do ensino que considere essa história (ROCKWELL, 1999).

\section{REVISITANDO A CASA ECOLÓGICA: UMA AULA CONTEXTUALIZADA}

A perspectiva acima nos ajuda a fazer sentido do complexo entrelaçamento de gêneros encontrados nas salas de aula durante meu estudo etnográfico nas 
escolas no centro de Tlaxcala ${ }^{11}$. As pequenas cidades nos morros mais baixos do vulcão Malintzin ainda estão inseridas na cultura naua, apesar de o uso da língua nativa mexicano, por muito tempo mantida numa relação sincrética com o espanhol dominante, estar rapidamente diminuindo (HILL e HILL, 1986). Na região, a vida dos vilarejos rurais está sendo progressivamente integrada à esfera urbana, ainda que os povoados mantenham fortes identidades locais. As escolas fundamentais mantidas pelo Estado se espalharam no final do século XIX e durante o movimento pós-revolucionário de escolas rurais nos anos 1920 (ROCKWELL, 1996). Nos idos de 1970, a maioria das escolas da região era mantida pelo governo federal e todos os professores tinham que adotar os livros didáticos nacionais gratuitos. Apesar do controle central, as instituições de formação e o ambiente cultural daquela região moldaram as tradições de ensino locais. Os professores, de fato, tinham considerável liberdade para desenvolver sua maneira particular de ensinar dentro das condições que lhes eram impostas, tais como salas com número elevado de alunos e relativa falta de recursos materiais.

Escolhi uma aula de 60 minutos para ilustrar a variedade de gêneros do ensino encontrada nesse contexto. Além de a transcrição ser excepcionalmente rica, observei a ocorrência da maioria dos recursos comunicativos que descrevo nesse caso também em outras salas de aula. O professor, a quem chamarei Pablo, era da região e compartilhava com seus alunos referências culturais comuns. Depois de 18 anos de experiência naquele distrito, trabalhava com mais de 30 alunos de sexta série $^{12} \mathrm{em}$ uma pequena escola rural. A cidade abrigava também um modelo de "casa ecológica" construída por uma organização não governamental. Assim, visitei a sala de aula um dia após o grupo ter feito um tour pela casa guiado pela bióloga residente. Durante essa aula, o professor guiou seus alunos num intenso e detalhado relato sobre o que haviam aprendido no dia anterior.

Enquanto fiz pesquisa nessa área, os professores estavam utilizando os livros didáticos de ciências produzidos durante as reformas dos anos $1970 .{ }^{13} \mathrm{~A}$ aula de ecologia estava atrelada ao capítulo sobre poluição no livro didático oficial da sexta série. O texto conta a história de duas crianças que visitam a Cidade do México e

11 Durante o início dos anos 1980, juntamente com vários colegas e estudantes, fiz um trabalho de campo de caráter etnográfico nas escolas primárias de duas municipalidades. Em vários períodos subsequentes $(1986,1992-93)$, concentrei-me em fazer entrevistas com professores e observar aulas nas séries mais avançadas de três escolas, enquanto completava uma pesquisa histórica sobre a história pós-revolucionária da escola nos arquivos estaduais.

12 No sistema educacional mexicano, a sexta série corresponde ao último ano do Ensino Primário e sexto ano de estudo dentro da estrutura da Educação Básica obrigatória e gratuita dos 6 aos 14 anos. A idade dos alunos varia em torno dos 11 anos. [NT]

13 Essa reforma envolveu, ambos, educadores e cientistas, que desenvolveram textos baseados na descoberta e em métodos experimentais então em voga. 
aprendem sobre poluição atmosférica; depois, o texto informa sobre as fontes de poluição do ar e da água em outras regiões. O manual do professor correspondente sugere passeios e experiências para detectar os efeitos da poluição no meio ambiente. Durante essa aula, Pablo não se referiu ao livro didático, apesar de indiretamente ter selecionado alguns pontos considerados no capítulo.

A aula foi similar a transcrições de discussões com grande grupo em sala de aula em outros contextos. O professor, em geral, tomou o turno alternadamente e os alunos responderam tanto individualmente quanto em grupo, algumas vezes, em uníssono. Em certos momentos, existia uma considerável simultaneidade (ERICKSON, 1996), com vários alunos tentando tomar o turno. Inicialmente, a participação individual ficou restrita a alguns alunos, mas, pouco a pouco, o professor conseguiu que outros estudantes também fizessem suas intervenções. Assim, o envolvimento coletivo dos alunos foi constante e apresentou tons e graus variados de entusiasmo. As sequências mais ricas aconteceram quando o professor desenhou ou pediu que alunos desenhassem instalações diferentes no quadro-negro e depois examinou detalhadamente cada processo.

Depois de lembrar aos alunos que eles deveriam falar um de cada vez e pensar antes de falar, Pablo levou a turma a descrever todos os aspectos da casa ecológica. Essa descrição incluiu: os materiais e técnicas usadas para construir e impermeabilizar as paredes; a cozinha ecológica; as fontes e usos de aquecimento e de fumaça; o galinheiro, o viveiro dos coelhos e o curral dos porcos; a coleta e purificação da água; o uso de energia solar; a estufa e o canteiro de verduras; e a sauna. A sequência temática foi co-construída à medida que os alunos se lembravam de cada etapa da visita. Entretanto, Pablo sempre retomava o tema central do texto: a noção de poluição. Ele assinalou as várias maneiras como a casa ecológica previne a poluição, da reciclagem de água ao controle de insetos, e comparou-as com as fontes de poluição ambiental na região, tais como o uso de tintas com chumbo e o despejo de detergentes no sistema de águas. A aula como um todo foi uma conquista coletiva, na qual os alunos fizeram intervenções, às vezes espontaneamente, e o professor acatou e complementou as versões que os alunos ofereceram. A aula serve, por isso, para ilustrar os quatro pontos mencionados anteriormente.

\section{O USO DE MÚLTIPLOS GÊNEROS NO ENSINO}

Ao longo da aula, Pablo usou uma variedade de gêneros conhecidos, embora poucos tenham sido nomeados; apresentou regras e definições, e referiu-se a histórias (cuentos) sobre as quais falara anteriormente. Suas tentativas de fazer piada 
algumas vezes provocaram risos. Também incorporou gêneros que normalmente são encontrados nas conversas cotidianas na região, tais como contos do passado, alguns ditos populares transmitidos através do discurso reportado e lições de moral advindas daí. Eu ainda identificaria aí determinadas formas de estruturar declarações, solicitar participação, chamar a atenção ou propor tópicos como instâncias de tipos de enunciados largamente usados por professores da região. Porém, não é meu propósito gerar uma lista de todos os gêneros que constituem nem mesmo uma só aula. Entretanto, defenderia que os diversos gêneros do discurso em jogo atuam juntos como uma única performance, e que a aula traduz, nos termos de Bakhtin, uma intercalação de muitos gêneros.

Uma percepção inicial da textura genérica dessa aula pode ser obtida a partir da observação dos gêneros que foram nomeados. Durante a aula, Pablo usou poucos termos que remetem à fala, mas dois deles denotam gêneros: plática ${ }^{14}$ (conversa informal ou bate-papo) e explicación (explicação).$^{15}$ Em várias ocasiões, ele chamou alunos para falar sobre (ou platicar) o que tinham visto e ouvido durante a visita. O professor usou explicar para referir-se à versão da bióloga ("Nos explicó que..." [Ela nos explicou que...]) e, em algumas ocasiões, às suas próprias intervenções. A sequência temática mais longa em que os dois termos foram explicitamente usados envolve a reconstituição de como o aquecimento e a fumaça do forno circulam e são usados para cozinhar ou fazer a cura da carne (defumar ou secar). O que segue é um excerto da sequência: ${ }^{16}$

14 "Plática" é um tipo de "conversación" ou "charla". O termo remete a uma conversação mais relaxada e amistosa. [NT]

15 Cada termo (tanto verbo quanto formas nominais) foi usado seis vezes. A contagem de palavras dessa transcrição revelou pouco uso de outros termos relacionados a gêneros.

16 A transcrição dessa aula, ministrada em 1993, é baseada em anotações feitas durante a aula e em gravações de áudio. Traduzo os excertos do espanhol. Muitos turnos são omitidos e os números referem-se apenas àqueles incluídos aqui. Uso os seguintes símbolos em todos os excertos:

$\mathrm{T}$

O professor fala.

Aluno Um estudante do sexo masculino fala (algumas vezes um nome é usado).

Aluna Um estudante do sexo feminino fala (algumas vezes um nome é usado)

Als

Vários estudantes falam, sobrepondo vozes ou em uníssono.

Pausa sem entonação descendente.

Pausa com entonação descendente.

Enunciado interrompido ou hesitação na voz.

? $\quad$ Entonação de pergunta.

! Tom de ênfase ou surpresa.

[ ] Sobreposição de turnos.

[....] Discurso transcrito, mas omitido no excerto ou incompreensível.

( ) Explicações contextuais ou esclarecimentos sobre sentidos ou referências implícitas.

A ausência de letras maiúsculas é intencional, já que a pontuação se refere à entonação e não à gramática. Os nomes são fictícios. 
Excerto 1. O forno ecológico

\begin{tabular}{|c|c|c|}
\hline 1 & P: & bem, um de vocês poderia falar a respeito (platicar) da cozinha ecológica? \\
\hline 2 & Als: & $\begin{array}{l}\text { [...] (Vários estudantes tentam falar. Juan, um estudante tímido, começa a } \\
\text { falar.) }\end{array}$ \\
\hline 3 & Juan: & (tem) um pedaço de madeira para o ... \\
\hline 4 & $P:$ & $\begin{array}{l}\text { (O professor manda Roberto, que já tomou mais turnos, ficar quieto.) vamos } \\
\text { ver, vamos ver, Juan vai dizer pra gente... }\end{array}$ \\
\hline 5 & Juan: & é uma (um tipo de) madeira (tábua) tal que... a carne não estraga... \\
\hline 6 & P: & e $[$ tem... \\
\hline 7 & Juan: & tem] uma porção de (pedaços de) metal. \\
\hline 8: & $P:$ & $\begin{array}{l}\text { uma tábua de modo que a carne não estraga, sim ... mas, primeiro ... onde } \\
\text { começa isso? (Vários estudantes levantam as mãos e tentam falar.) }\end{array}$ \\
\hline 9 & Als (vários): & {$[$ com um forno! o forno...] } \\
\hline 10 & Roberto: & $\begin{array}{l}\text { em um forno due ...chamam de tlecuil, }{ }^{17} \text { (é onde) o fogo passa ... (lá) eles } \\
\text { colocam as tortilhas ... (lá) você pode fazer muita coisa ... }\end{array}$ \\
\hline 11 & $P:$ & que tal desenhar isso pra mim?...eu ajudo você... $[\ldots .]$. \\
\hline
\end{tabular}

(O professor começa a desenhar no quadro o forno mencionado, então Roberto e, depois, Maria desenham as partes, enquanto os outros que estão sentados gritam os detalhes que devem ser adicionados. Desse ponto em diante, várias trocas de turno se sucedem entre os próprios estudantes e entre o professor e alguns estudantes até o desenho ficar pronto, quando o professor retoma.)

$12 P:$

13

14

15

16

17

18

19
Als:

$P$ :

Aluna:

$P$ :

Als:

Als:

$P$ :
[.... ( $\mathrm{O}$ professor muda ligeiramente o tom como se iniciasse alguma coisa nova e aponta para as partes do desenbo.) ok, vejamos, em primeiro lugar ... a explicação (explicación, com ênfase) sobre a cozinba ecológica...o que foi que ela nos disse? ... ele (o forno) evita o cansaço ... das pessoas que fazem as tortilhas, não é? [...] como é fazer tortilhas...ficar de joelhos lá (no chão)? É bom? (ele já havia falado sobre isso previamente com as alunas e levanton o assunto novamente aqui.)

[ñ̃o! ñ̃o!]

os joelhos cansam, certo?

sim!

seus joelhos cansam ...e o que mais cansa?

[as costas! as costas!]

$[\ldots$.

[.... então, vejam aqui, então, os ecologistas ... o que eles dizem?... construímos uma espécie de forno, certo? [...] nessa parte nós atiçamos of fogo (apontan-

17 Esse é um dos muitos termos na língua náuatle usados espontaneamente durante a aula que deixo na sua forma original. 


Als (vários):
$P:$
As (vários):
$P:$
Als (uníssono):
$P:$

Als (uníssono) $P$ : do para a parte do desenbo)...certo?...atiçar significa ... que colocamos o que adui?

[madeira ... madeira]

madeira ... certo? ... e certamente aqui (apontando para a parte do desenbo) é onde alguém vai ficar para fazer as tortilhas.

$[\operatorname{sim} \ldots \operatorname{sim}]$

e nessa parte ...está ... o comal (um utensílio plano para cozinbar tortilbas).

sim!

certo? ... (Ele continua apontando para as partes do desenbo.) mas, então, aqui eles instalaram algumas pequenas tubulações, não é? ... assim o vapor pode passar através delas. e aqui colocamos uma panela de feijão, ou um bule de chá, ou uma papeiro de atole (mingau), o que quiser, certo? ... aqui, vamos também colocar (adicionando ao desenbo) ... bem aqui, está outra, a mesma, instalação ... e isso está também conectado à uma tubulação. e aqui está um outro tipo de comal pequeno, do mesmo jeito, que você pode usar para cozinbar carneiro, certo?... e, assim, bem aqui é onde a chaminé começa, a chaminé, aquela ... qual era mesmo o procedimento que nos falaram ontem? ... que isso leva a fumaça para cima. (O tempo inteiro, ele se refere às partes do desenbo.)

sim!

mas a madeira é muito eficaz [...] eu não sabia disso. eu sabia que bavia carne defumada ... mas a técnica [.... nos frigoríficos é diferente ... lá eles jogam serragem (no forno) e depois açúcar [...] e acendem, mas com gás! [...] e é a fumaça que cozinha a carne! [...] mas, além disso, eles adicionam um preservativo ... chamado fumaça! (Pablo continua por mais um minuto discutindo todo o processo de defumar carne em cada caso.)

O mais significativo nesse trecho é o professor ter mencionado as formas de discurso a serem usadas. Na primeira parte, o professor fez os alunos relatarem (platicar, na linha 1) o que recordavam sobre a cozinha e depois desenharem no quadro. Há uma quebra na sequência, sinalizada pela frase "ok, vejamos, em primeiro lugar ... a explicação" (linha 12). Depois ele se referiu ao desenho para lembrar a explicação que a bióloga deu sobre como a cozinha funcionava, mais particularmente, como a fumaça era canalizada para defumar a carne.

Há muitas razões para se considerar plática e explicación como gêneros. Em primeiro lugar, o uso particular dos termos nesse contexto fundamenta tal afirmação. Por exemplo, Pablo usou bablar (falar) para fazer os alunos pararem de falar entre si ou fora do turno. Embora hablar e platicar sejam quase sinônimos, nesse caso específi$\mathrm{CO}$, apenas platicar sugeriu um gênero que remete a um modo particular de expressar conhecimento e, assim, deu espaço para turnos descritivos relativamente abertos por parte dos alunos. A acentuação utilizada (na linha 12) sugere que o professor distinguiu explicación como um modo diferente de falar. 
Evidências em cenários não escolares confirmam a configuração da plática como um gênero (ROCKWELL, 1992). Plática remete a um tipo de conversação em que pelo menos um dos participantes faz um relato mais amplo de uma experiência que viveu (usando, com frequência, a primeira pessoa), como, por exemplo, um evento ou um encontro, geralmente para alguém que não compartilhou a experiência. O termo implica mais do que uma conversação (em espanhol, conversación) e sugere um testemunho detalhado que é dado de forma convincente tal que os ouvintes sejam levados a imaginar o que foi vivenciado. Neste caso, se os pais dos alunos tivessem questionado seus filhos sobre a casa ecológica, eles provavelmente usariam o mesmo verbo. A plática pode ocorrer com estruturas de participação distintas. Quando uma pessoa mais velha faz uso da plática, espera-se que os demais ouçam atentamente; já os filhos e amigos tendem a participar de forma mais simétrica, falando entre si sobre experiências similares.

Em espanhol, o termo explicación, comparado à plática, geralmente implica um ouvinte já familiarizado com o tópico ou compartilhando a experiência naquele exato momento. Assim, uma de suas características é o uso mais amplo de dêiticos, ou seja, expressões que remetem a elementos contextuais. Ao explicar, o falante pode entrar em detalhes sobre como alguma coisa funciona ou acontece, recapitulando um processo. A bióloga residente usou a explicación dentro de uma estrutura bastante formal, com pouca participação dos alunos, para dar informações que os alunos não poderiam inferir simplesmente observando as instalações ${ }^{18}$. Enquanto a plática dá os fundamentos do conhecimento relativos a uma experiência particular, a explicación assume que o falante tem alguma expertise não prontamente acessível aos que não têm experiência. Contudo, os dois gêneros são usados para expressar conhecimento, daí suas potencialidades na educação.

Como esses modos de falar apresentam certas características genéricas em cenários não escolares, eles podem ser vistos como gênero também na sala de aula. No exemplo acima (excerto 1), em vez de apontar para partes da interação como configurações de um ou outro gênero, sugeri que se observasse como se misturam na conversação em curso. Como resposta à solicitação do professor pela plática, os alunos procuraram dizer o que viram na cozinha. Um descreveu a base de madeira usada para secar carne (linhas 3, 5 e 7) e outro o forno (linha 10). Mas eles também usaram frases que provavelmente selecionaram das explicações dadas pelo biólogo (por exemplo, "é uma (um tipo de) madeira (tábua) tal que... a carne não estraga ...", linha 5).

18 Embora eu não estivesse presente quando a turma fez o tour pela casa, fiz a visita previamente e recebi uma explicação similar. 
Quando nos voltamos para o discurso do professor, podemos também observar o uso dos dois gêneros. Pablo explicitamente repetiu algumas das explicações dadas pela bióloga, por exemplo, quando mencionou a forma como o fogo é aceso (linha 19) e o modo como a fumaça passa através da tubulação e é usada para defumar a carne (linha 25). Porém, ele também inseriu alguma plática na explicação da cozinha, particularmente quando falou para os alunos como a carne defumada que é comercializada é feita (na linha 27, observe o uso de "Eu sabia"). Claro que essa pequena amostra de plática continha alguma explicação e serviu para ressaltar ainda mais a importância de usar fumaça de verdade (e não um produto químico) na casa ecológica.

Assim, a imbricação de plática e explicación produziu um gênero secundário e imprimiu à aula sua coerência mais geral como performance. Esse padrão caracterizou grande parte da interação observada ao longo dessa e de outras aulas, particularmente em ciências, que observei na região.

\section{ADAPTANDO GÊNEROS DO DISCURSO PARA A CONVERSA DE SALA DE AULA}

Quando determinados gêneros do discurso emergem nas conversações em curso na sala de aula, eles sofrem e provocam mudanças, uma vez que as condições de sala de aula diferem de outras situações em que os gêneros são utilizados. Nessa aula, a diferença mais evidente foi na estrutura de participação. Diferentemente da estrutura de uma conversa familiar local (em que pode haver muitos adultos e diferenças consideráveis de idade) ou do tour pela casa ecológica (com poucos diálogos), a participação nessa sala de aula foi marcada pela interação verbal contínua entre um único adulto e um grande grupo de pares. Pablo adaptou os gêneros plática e explicación para esta estrutura. Como ele alternou o uso dos gêneros em seu discurso, continuou a solicitar e admitir intervenções dos alunos, que eram, por vezes, expressas nas mesmas formas genéricas.

Outras condições distintas da situação de sala de aula são menos óbvias, tais como se os falantes compartilham ou não o conhecimento que está sendo comunicado através de gêneros específicos. A plática tende a surgir em situações em que o ouvinte não tem uma experiência compartilhada; no entanto, neste caso, ambos (alunos e professores) visitaram a casa ecológica. Talvez, isso explique certa reticência que os alunos inicialmente tiveram em falar da casa, embora eles possam também ter sido cautelosos com algumas das primeiras reações do professor ${ }^{19}$. Um pedido de plática deverá permitir aos estudantes a responder à vontade, mas esse, em par- 
ticular, pode ter esbarrado com uma exigência implícita de uma "resposta pronta". No entanto, Pablo encorajou a fala de uma maneira que eu tinha observado entre muitos professores mais velhos na região: ele alegou "não saber". Durante várias vezes, ele disse que "não estava lá" ou que "lembrava pouco". Esta simulação de ignorância não causou nenhuma surpresa nos alunos, uma vez que vários responderam ao pedido de plática e acrescentaram explicações recebidas durante a visita. Assim, o recurso do professor ajudou a restaurar uma das condições sociais para o uso do gênero: a de dizer algo novo para o ouvinte. Enquanto a aula prosseguia, alguns alunos deram informações que o professor tinha, aparentemente, perdido durante a visita; e foi, em momentos assim, que a plática do aluno foi mais intensa, como no excerto a seguir:

Excerto 2. Luz solar

P: o que mais? [...] porque me lembro que saí um ponco (muitos alunos falaram) $[. .$.

Aluno: outra coisa! eb a luz solar. bá uma tipo de vidro, acima, e toda a luz solar cai sobre esse vidro e eb... é por isso que à noite, quando não bá luz solar, bá uma bateria, com uma bateria de carro, e lá eles conseguem tudo, eles não precisam mais do sol! ... [...] sim mas durante o dia eles não usam a bateria, apenas a luz solar.

P: eles podem utilizar para lâmpadas! sim! eu não cheguei a ver isso, porque eu não estava lá dentro nesse momento ... [.... eu não ouvi sobre isso. bom! o que mais?

Da mesma forma, Pablo era mais eloquente na plática, compartilhando informações sobre experiências que os alunos não tinham vivenciado. Tal foi o caso de seus comentários sobre o processo de comercialização para curar carnes (excerto 1, linha 27), que, como eu soube mais tarde, foram baseados em sua própria experiência anterior de trabalho em um frigorífico. Em alguns pontos, seu uso da plática evoluiu para um gênero mais formal, usado frequentemente na região: o relato pessoal. Recursos narrativos, tais como a ordem sequencial, uso de primeira pessoa, verbo no passado, discurso direto e repetição, marcaram estes momentos. Nessa direção, esses recursos sugerem que Pablo tinha contado as histórias antes, pois algumas crianças responderam de forma característica à narrativa conversacional em cenários não-escolares, repetindo tópicos frasais como perguntas, como no exemplo a seguir:

19 Ver excerto 1: "sim... mas, primeiro..." (Linha 8). Outro fator foi a minha presença como observadora: uma vez que Pablo, em primeiro lugar, pediu aos alunos para me contar sobre a casa. 
Excerto 3. Uma experiência da infância

P: nós... bem ... eutrabalbava lá, em alguns galinheiros.e para desinfetar os galinbeiros, [.... nós tivemos que misturar cal com sal.

Aluno: cal com sal?

P: sim! com sal. para pintá-los, primeiro limpava todos os excrementos, o esterco de galinba. a gente tinha que varrê-los muito bem e depois lavar o chão, utilizando um monte de água. e após a lavagem, a gente tirava o pó de tudo. e depois vem a pintura, com cal, tudo bem? para desinfetar. [...] então passamos cal nas paredes, e em todos os cantos, porque o mofo permanece pelos cantos, os germes, e então causam doenças, e assim as galinhas, eles dizem, começam a se queixar. [...] então, eles me ensinaram que aquela técnica, eles disseram, você tem que caiar tudo com cal e sal. isto é, os sacos de cal estavam misturados [...] em tambores grandes, e depois eles jogavam lá dentro o sal, pedaços de sal, aqueles (que são) como pedras. (Pablo continua por mais ou menos um minuto contando como ele caiava as paredes, e, de vez em quando, alguns alunos repetem as frases).

Uma maneira diferente, na qual o contexto de sala de aula muda as condições que cercam o uso de um gênero, pode ser vista no caso da explicação (explicación). Pablo reafirmou algumas das explicações da bióloga sobre como certos recursos da casa funcionavam. No entanto, ao contrário do que acontecera durante a visita, as instalações que foram o objeto dessas explanações não estavam mais presentes. Dentro deste contexto, para que a explicação fizesse sentido como um gênero, o professor teve que recriar a experiência compartilhada e recuperar o objeto da explicação. Pablo conseguiu isso, em parte, através da plática que forneceu descrições verbais da casa, e, em parte, por meio dos desenhos. Neste sentido, as explicações, geralmente, seguiram sequências em que os alunos falaram sobre o que tinham visto na casa. Além disso, muitos enunciados explicativos foram marcados por referência dêitica em direção aos desenhos, como no excerto 1: "nessa parte nós atiçamos o fogo" (linha 19, ênfase adicionada); "bem aqui é onde a chaminé começa" (linha 25, ênfase adicionada). A plática permitira ao professor utilizar eficazmente a explicação, alterando o ambiente discursivo da sala de aula ao introduzir um ponto de referência compartilhado em um contexto marcado, geralmente, pela conversa sobre objetos distantes. Assim, Pablo repetiu esse padrão nos muitos temas de que tratou durante a aula.

Como os professores incorporam na sala de aula os gêneros usados em diferentes domínios sociais, eles os adaptam às novas condições de conhecimento compartilhado ou não e de referência contextual. Parafraseando Bakhtin (1986: 62), quando os gêneros primários integram os secundários, eles perdem o vínculo imediato com a realidade concreta e adquirem um sentido novo com referência a 
elementos internos. A lógica do ensino envolve esses gêneros e os moldam para as tarefas em questão. No entanto, os professores não só modificam os gêneros utilizados; eles também constroem ativamente as condições discursivas que facilitem o aparecimento de certos gêneros na sala de aula. Ao utilizar recursos tais como alegar "não saber", compartilhar experiências pessoais e representar o objeto através de desenhos, Pablo reconstruiu algumas das características de contextos não-escolares que tornaram plausível o uso da plática e da explicação (explicación) na sala de aula. A recriação verbal e visual da experiência compartilhada define o cenário para co- construir uma versão da casa ecológica relevante para o tópico em jogo ${ }^{20}$.Com este frame básico, Pablo utilizou outras formas genéricas extraídas do balanço das tradições de ensino local para transmitir conhecimentos sobre o meio ambiente.

\section{Representando conhecimento através de gêneros}

Uma dimensão crucial dos gêneros é a sua associação com conteúdos específicos. Nas palavras de Bakhtin: "gêneros correspondem a (...)alguns contatos típicos dos significados das palavras com a realidade concreta em certas circunstâncias típicas" (1986:87). Os gêneros não se realizam ao longo do tempo como estruturas abstratas ou ferramentas (vazias de significados) a serem aplicadas a qualquer conteúdo temático. Pelo contrário, eles carregam consigo pensamentos, valores e sentimentos que são (re)vozeados e re-interpretados em cada situação nova. O conhecimento, por outro lado, é sempre expresso em formas genéricas; uma vez que não tem outra maneira de existir publicamente. Conteúdos específicos e "categorias de ideias" são apresentados na sala de aula através dos gêneros que os professores usam. No exemplo acima, Pablo seletivamente representou, na sala de aula, a experiência na casa ecológica (re)vozeando tanto as explicações da bióloga quanto o relato dos alunos. Durante a aula, o professor incorporou também outros gêneros para representar aspectos particulares do saber.

No ensino fundamental no México, como em outros países, os professores usam formulações convencionadas de conteúdos específicos: definições precisas, esquemas classificatórios e algoritmos são ocorrências comuns. A estrutura taxonômica de muitos conhecimentos escolares, sobretudo nas ciências, é ela própria uma espécie de gênero (LEMKE, 1990): uma maneira codificada de apresentação de conteúdos que tende a permanecer dentro das tradições do ensino de sala de aula, apesar das mudanças em outras esferas. Em certos momentos, como quando

20 Pablo conseguiu mais participação nesta aula que quando ele apresentava temas que estavam muito distantes tanto da sua experiência quanto do cotidiano das crianças, tais como a evolução humana. 
solicitara uma definição de ecologia, Pablo usou uma frase convencional, característica de alguns livros didáticos: "é a ciência que estuda o quê...?". Quando questionou os alunos sobre exemplos de classes e subclasses, a representação genérica do conhecimento tendeu a padronizar o próprio discurso. Assim, o docente suscitou várias respostas sobre tipos de clima com a seguinte consulta: "e dentro de clima, nós temos...que tipos?".

Embora a influência desta linguagem científica seja considerável, a maioria dos professores da região tende a integrar outros tipos de gêneros, como as metáforas e as analogias, para reforçar as definições ou esclarecer conceitos. Nesta aula, por exemplo, Pablo explicou a vida de uma árvore, referindo-se ao ciclo da vida humana. Os professores locais veem essas aparentes digressões como forma de enriquecer e ampliar as representações, bastantes áridas, do conhecimento científico convencional, aproximando-o assim da experiência cotidiana das crianças.

Muitos dos professores mais velhos na região transmitiam conhecimentos complementares através de gêneros narrativos. Como vimos anteriormente (excerto 3), Pablo usou suas consideráveis habilidades narrativas - na forma de plática - para apresentar sua experiência pessoal. Repetiu também trechos do folclore local e lendas que alguns alunos poderiam identificar, com a história de Quetzalcoalt, um deus naua, e da fumaça. Tanto a variedade de gêneros quanto as nuances de sentido que eles acrescentaram sugerem o caminho que o saber local se inscreveu no ensino de sala de aula. Por exemplo, a versão de Pablo sobre o destino da floresta Malinche (ver abaixo) foi quase idêntica a muitas que ouvi de veteranos e ecoou imediatamente nos alunos:

Excerto 4. A Floresta Malinche

P: quando estudamos ecossistemas eu disse a vocês que aqui em Malinche, muito tempo atrás, muitos anos atrás, quando eu ainda não era nascido, a Malinche teve vida uma bonita vida selvagem [.... . (havia) animais como [lobos

Alunos: (muitos diziam em voz alta diferentes animais, embora não tivessem sido solicitados pelo professor.) [lobos. veados. coiotes. pássaros.]

P: coiote, veado, pássaros...esplendorosos $]$ aves. era tudo muito bonito [.... e por aqui, era cheio de árvores, porque nós vivemos nos morros mais baixos de Malinche.

Certamente, o folclore não é inserido na sala de aula sem alterações. As histórias são reacentuadas, uma vez que as versões eram "transmitidas em tons irônicos, indignados, simpáticos e reverentes [e nelas] se cruzam, convergem e divergem diferentes pontos de vista, visões de mundo, correntes" (BAKHTIN 1986: 92-93). 
O dialogismo interno de todo discurso é evidente nesses enunciados. No exemplo a seguir, Pablo distanciava-se com frases como "não sei mais o quê!", enquanto atestava, ao mesmo tempo, a sua familiaridade com a cultura regional e se lembrava das recomendações da bióloga.

Excerto 5. O cheiro de coelhos

P: tirar as gaiolas de coelho. os animais são tão bonitos, não? mas é difícil suportar o cheiro dos coelhos. na verdade, as pessoas nas cidades acreditam, não? que eles fazem muito mal para as meninas. porque, dizem, quem sabe o quê? ... que elas não vão se casar e não sei mais o quê! ... dizem que você deve manter os coelhos longe, não muito perto da casa. [...] eles contaram para a gente (na casa ecológica), pelo contrário, que o cheiro vem da (amônia na) urina, e é isso que ajuda a desinfetar.

As formas genéricas transmitem conhecimentos. Os gêneros usados pelos professores vêm carregados de componentes específicos e de significados. Através do uso de diversos gêneros, Pablo trouxe versões da bióloga, taxonomia de livros didáticos, histórias pessoais e do folclore local, enquanto co-construía o conteúdo específico da aula com o grupo. $\mathrm{O}$ uso de múltiplos gêneros torna o conhecimento beteroglóssico, no sentido fortemente bakhtiniano; cada enunciado ecoa, distorce, elabora ou questiona representações paralelas e anteriores do conhecimento.

\section{A INFLUÊNCIA GENÉRICA DAS TRADIÇÕES DE ENSINO LOCAIS}

Bakhtin (1984: 106) sugere que o estudo das origens dos gêneros ajuda a conectar o uso situado da linguagem com seu contexto histórico. Sob essa perspectiva, os gêneros utilizados no discurso de sala de aula podem ser vistos como refletindo as tradições locais de ensino. A vida de Pablo atravessou um período específico na cultura local de ensino. No curso da sua vida e de sua carreira, ele se apropriou e remodelou certos gêneros e práticas, encontrados neste ambiente específico. Apesar de os estilos de ensino na região estarem longe de ser uniformes, alguns padrões recorrentes sugerem processos locais de codificação de gêneros do ensino e, até mesmo, remontam às prescrições centenárias para o ensino.

Por exemplo, há alguns indícios que sugerem que tanto a plática quanto a explicação (explicación) tinham sido, explicitamente, incorporados por essa cultura local de ensino. Durante uma entrevista, Pablo falou de alguns dos professores de que ele tinha gostado enquanto criança, acrescentando que estes davam "uma ampla explicação" dos conteúdos dos livros didáticos. Enquanto me contava sobre seus 
anos no instituto de formação de professores, Pablo destacou aqueles professores que eram capazes de falar longamente (plática) sobre um tema sem se referir a anotações ou a livros, uma característica valorizada pelos outros professores mais velhos na região, apesar de não ser colocada em prática por todo ${ }^{21}$. Tinha menos em conta os professores mais jovens que, após enviar os futuros professores para pesquisar um tópico na biblioteca, esclareciam apenas as suas dúvidas (sacarnos de duda). Parece possível que o fato de tanto a plática quanto a explicación serem valorizados, pelo menos por alguns professores, dentro da atmosfera genérica local, tenha influenciado o desenvolvimento de Pablo como professor.

Outra origem para esta tradição de ensino é o discurso escrito dos livros didáticos oficiais mexicanos, distribuídos gratuitamente para todos os alunos a cada ano. No entanto, a influência destes livros não era imediata, mas, sim, filtrada ao longo do tempo. Ao ensinar a lição sobre ecologia, um tema que era relativamente recente no currículo da escola fundamental, Pablo fez uso de temas relacionados, tais como eram apresentados no conjunto de livros didáticos gratuitos que possuíra enquanto criança. As lições sobre o clima, erosão do solo e recursos naturais naqueles textos combinavam definições bastante elaboradas e esquemas taxonômicos com conselhos práticos sobre preservação. Apesar de esses tópicos já não aparecerem nos livros didáticos em uso, eles eram incluídos nos exames de acesso à escola secundária local ${ }^{22}$, e, portanto, muitas vezes abordados pelos professores da sexta série. Pablo acreditava que os novos livros didáticos não dispunham de informações específicas sobre termos e definições, e, por isso, ele consultava os livros mais antigos.

Nesta cultura particular de ensino, parece que, ao contrário dos gêneros que representam os conteúdos científicos, as histórias e os relatos pessoais não passam facilmente do livro didático para a fala. Pablo não reconta a história do capítulo de poluição do novo livro didático, escrita em um estilo distante da experiência real da criança. Em vez disso, ele repetiu histórias pertencentes à tradição oral, que eram pertinentes ao tópico em questão e que fazem parte da tradição mais geral de ensino na região. As histórias sobre a floresta Malinche (excerto 4), por exemplo, apareceram em diferentes salas de aula, por vezes, em versões idênticas ou transmitindo mensagens semelhantes. Em todo caso, ficou evidente que o discurso de sala de aula não desenvolvia, sistematicamente, o roteiro do livro didático oficial corrente, mas, sim, refletia uma construção de longo prazo em que o conhecimento escolar e as culturas locais se entrelaçavam.

21 Um supervisor mais velho tinha defendido esta competência em outra entrevista.

22 O Ensino Secundário é gratuito e obrigatório no México; corresponde a três anos e começa após a sexta série do Ensino Primário, com estudantes na faixa dos 12 anos de idade. [NT] 
As forças de formação de um gênero podem ser traçadas muito além do tempo em que viveu um professor e em direção aos métodos de ensino que foram introduzidos no passado. Há dois exemplos nas sequências acima apresentadas. O comentário sobre a forma como se sente ao fazer tortilhas, no excerto 1 (linha 12), ecoa o discurso dos professores rurais pós-revolucionários da década de 1920, que relacionavam, continuamente, os conteúdos escolares com as necessidades sociais das comunidades. O comentário sobre coelhos (excerto 5) mostra traços do uso de explicação científica do século XIX para "erradicar a superstição", que se intensificou durante o período da educação socialista na década de 1930. Apesar de essas serem peculiaridades das tradições de ensino locais ou nacionais, até o início dos anos 90, nem todos os professores da região haviam recuperado essas fontes genéricas particulares.

A aula sobre ecologia também mostra rupturas com padrões discursivos do passado, como com o gênero catequese que os educadores do século XIX resgataram da Igreja Católica para incutir uma nova consciência cívica nacional. No fim de 1917, o protocolo de um modelo de aula de ciências para professores que treinavam em serviço naquela região registrava "um catecismo dirigido aos alunos sobre o tema", apesar de simultaneamente pedir aos professores "para não inculcar as respostas por memorização ${ }^{\prime \prime 23}$. Apesar de as respostas em coro, que ainda apareceram na aula acima (excerto 1, linhas 24 e 26), poderem ser uma reminiscência dessa tradição, Pablo não usou um conjunto fixo de perguntas e resposta, lembrando muitas vezes as crianças para não responderem em uníssono, mas um de cada vez. O catecismo é, provavelmente, uma influência relativamente distante em sua forma de ensinar e o próprio termo já não era ouvido nos meios educacionais locais.

Juntos, esses traços sugerem que os gêneros do ensino mudam gradualmente; os professores substituem os gêneros preexistentes e alteram ou recombinam outros para atender a novos objetivos. No entanto, mesmo dentro desta região, os gêneros do ensino decorrentes são heterogêneos, refletindo influências históricas distintas. $^{24}$

23 Resumo da conferência ocorrida no sábado, vinte e cinco do mês de agosto de mil novecentos e dezessete no salão destinado a Escola Elementar de Santa Cruz, Tlaxcala, e presidida por C., Inspetor Técnico-administrativo da Segunda Zona Escolar, Professor Bernabé Barrera. Arquivo Geral do Estado, Fundo de Revolução e do Regime Obregonista, Caixa 344/3, 1917.

24 Descrevi algumas diferenças em outros trabalhos (ver ROCKWELL, 1995). 


\section{ESTUDANDO GÊNEROS DO ENSINO}

Baseada no trabalho de Bakhtin, assumi, em primeiro lugar, que a aula pode ser considerada como um gênero secundário ou "multigenérico", que combina uma variedade de gêneros primários usados em outros contextos. Alguns gêneros trazidos de outros domínios passam por processos de formalização específicos no interior das práticas de ensino, enquanto outros são incorporados no calor do momento. Em segundo lugar, que gêneros particulares se imbricam nas "longas conversações" que acontecem entre professores e seus alunos, tal como são incorporados nos diferentes tipos de romances estudados por Bakhtin. A performance do ensino não segue um script único; ao contrário, requer habilidade para integrar formas genéricas diversas e construir o ambiente discursivo para que funcionem na sala de aula. Em terceiro lugar, que os gêneros utilizados no ensino não são formas abstratas, mas carregam, sim, sentido e conteúdo e refletem o registro de experiências pessoais, do folclore local ou do conhecimento acadêmico. Finalmente, que os gêneros do ensino têm histórias. As misturas particulares que formam as tradições de ensino mudam com o tempo e se desenvolvem de modos particulares, em contextos regionais diferentes.

A aula de Tlaxcala que uso acima, particularmente, ilustra bem esse processo. Tento mostrar como dois gêneros nomeados pelo professor, plática e explicación, foram incorporados à aula, oferecendo possibilidades para ambos, professores e alunos, dar voz a sua própria experiência e a seu próprio conhecimento. Na tradição de ensino que atua nessa aula, o conteúdo foi representado por meio de gêneros como as definições, construídas para expressar o conhecimento científico, e lendas ou histórias usadas para falar do saber pessoal e local. Neste exemplo, busco as influências do gênero nos modos de falar enquanto se ensina textos escritos, nas tradições de ensino mais remotas e nas práticas culturais proximamente relacionadas.

Para concluir, gostaria de somar alguns pensamentos às futuras investigações sobre gêneros do ensino. Sem dúvida alguma, enquanto muito da pesquisa em sala de aula continuará a explorar as conexões entre os gêneros do ensino e a aprendizagem, defendo que se reforce o nosso frame comparativo de referência e se incorpore um senso mais profundo de história à pesquisa sobre ensino (ROCKWELL, 1999). Mapeando os gêneros do ensino dentro e entre regiões, podemos aumentar a nossa compreensão sobre a natureza cultural do ensino e os modos diversos através dos quais os estudantes oriundos de outras sociedades vivenciaram o processo de escolarização no passado. Isso requer que se use não apenas as ferramentas da etnografia, mas, também, da etnologia e da etno-história. 
A análise de gêneros ajuda a compreender como os professores agem com as palavras e como esses modos de agir mudam com o passar do tempo. Os gêneros do ensino oferecem pistas sobre a sistematização do conhecimento escolar e a sua tradução em currículos vivos e, também, sobre o jogo entre tradição e inovação no ensino. Embora uma pesquisa documental sobre as interações em curso em sala de aula no passado seja praticamente impossível, as gravações de áudio e vídeo de atividades de ensino durante as últimas três décadas e, também, a comparação entre as diferentes gerações de professores feitas atualmente deveriam oferecer evidências dessa dimensão temporal. Por meio de uma investigação das influências dos gêneros no ensino, podemos estudar a disseminação e a transformação das práticas de ensino e, também, antecipar como as mudanças podem ocorrer no futuro.

A pesquisa cultural e histórica sobre o ensino pode também abordar a permanente preocupação com as consequências da escolarização. A análise dos gêneros do ensino pode responder questões suscitadas pelos estudos críticos sobre educação, inclusive a relação entre o discurso pedagógico e certos processos, tais como os de imposição do pensamento "ocidental" e de desenvolvimento do "pensamento crítico". Podemos descrever melhor os contornos do ambiente discursivo dentro do qual a aprendizagem escolar se desenvolve. O material genérico do ensino é permeado com estruturas e mecanismos retóricos - as categorias de pensamento de Bakhtin - que são normalmente invisíveis à própria cultura em que se inserem (SWALES, 1990, p. 64-66). Essa questão aponta para o debate atual sobre a opção de se ensinar e como ensinar gêneros dominantes e suas regras subjacentes ou, ao contrário, de se admitir e estimular os diversos modos de falar, escrever e pensar na escola (CAZDEN, 1996; GEE, 1996).

Discutindo a dimensão social do ensino, podemos ficar mais atentos ao que Bakhtin vê como a necessidade de "uma abordagem particular dos gêneros do discurso [...] que reflita de forma mais direta, clara e flexível todas as mudanças que acontecem na vida social" (1986, p. 65). Esse caminho vai manter os esforços para relacionar os modos de falar a questões sociais fundamentais de identidade, ideologia e poder. Ao explorarmos o caráter flexível, dinâmico e, às vezes, subversivo do uso de gêneros na sala de aula, podemos também observar "o poder inerente ao desempenho de transformar as estruturas sociais" (BAUMAN, 1977, p. 47-48).

\section{REFERÊNCIAS BIBLIOGRÁFICAS}

ANDERSON-LEVITT, Kathryn M. (2002). TeacbingCultures: Knowledge for Teaching First Grade in France and the United States. Cresskill, NJ: Hampton Press. 
BAKHTIN, Mikhail. (1984). Problems of Dostoevsky's Poetics. Minneapolis: University of Minnesota Press.

(1986). The Problem of Speech Genres. In: Speech Genres and Other Late Essays. Caryl Emerson and Michael Holquist, Eds. Austin: Universtity of Texas Press, pp. 60-102. BALLENGER, Cynthia. (1997). Social Identities, Moral Narratives, Scientific Argumentation: Science Talk in a Bilingual Classroom. Language and Education 11 (1): 1-14.

BAUMAN, Richard. (1977). Verbal Arts as Performance. Prospect Heights, Il: Waveland Press. BRIGGS, Charles L. (1988). Competence in Performance. Philadelphia: University of Pennsylvania Press.

BRIGGS, Charles L.; BAUMAN, Richard. (1992). Genre, Intertextuality and Social Power. Journal of Linguistic Antbropology 2 (2): 131-172.

BRONCKART, Jean-Paul. (1994). Lecture etécriture: élements de synthèse et de prospective. In: Les Interactions lecture-écriture. Yves Reuter, ed. New York: Peter Lang, pp. $371-404$.

CANDELA, Antonia. (1999). Student's Power in Classroom Discourse.Linguistics and Education. 10: 1-25.

CAZDEN, Courtney. (1988). Classroom Discourse: The Language of Teaching and Learning. Portsmouth, NH: Heinemann.

(1996 ). Selective Traditions: Reading of Vygotsky in Writing Pedagogy. In: Discourse, Learning and Schooling. Debora Hicks, ed. Cambridge: Cambridge University Press, pp. 165-185.

CHRISTIE, Frances. (1987). Young Children's Writing: From Spoken to Written Genre. Language and Education 1 (1) 3-13.

DE CERTEAU, Michel. (1994). La cultura plural. Buenos Aires: Nueva Visión.

ERICKSON, Fredrick. (1996). Going for the Zone: The Social and Cognitive Ecology of Teacher-Student Interaction in Classroom Conversations.In: Discourse, Learning and Schooling. Deborah Hicks, ed. Cambridge: Cambridge University Press, pp. 29-62.

FOLEY, Douglas. (1990). Learning Capitalist Culture: Deep in the Heart of Tejas. Philadelphia: University of Pennsylvania Press.

FOSTER, Michèle. (1995 ). Talking that Talk: the Language of Control, Curriculum and Critique. Linguistics and Education 7: 129-150.

FREEDMAN, Aviva; MEDWAY, Peter. (Orgs.). (1994). Genre and the New Rhetoric.London: Taylor and Francis.

GEE, James. (1996 ). Vygotsky and Current Debates in Education: Some Dilemmas as After-thoughts to Discourse, Learning, and Schooling. In: Discourse, Learning and Schooling. Deborah Hicks, ed. Cambridge: Cambridge University Press, pp. 269-282.

HICKS, Deborah. (1996 ). Contextual Inquires: a Discourse-Oriented Study of Classroom Learning. In: Discourse, Learning and Schooling. Deborah Hicks, ed. Cambridge: Cambridge University Press, pp. 104-141. 
HILL, Jane; HILL, Kenneth. (1986 ). Speaking Mexicano: Dynamics of Syncretic Language in Central Mexico. Tucson: University of Arizona Press.

KOZULIN, Alex. (1996). A Literary Model for Psychology. In: Discourse, Learning and Schooling. Debora Hicks, ed. Cambridge: Cambridge University Press, pp. 145-164.

KRESS, Gunther. (1997). Before Writing: Retbinking the Path to Literacy. London: Routledge.

LEMKE, Jay L. (1990). Talking Science: Language, Learning and Values. Norwood, NJ: Ablex.

MANNHEIM, Bruce; TEDLOCK, Dennis.(Orgs.). (1995 ). The Dialogic Emergence of Culture. Chicago: University of Illinois Press.

MAYBIN, Janet. (1994 ). Children's Voices: Talk, Knowledge and Identity. In: David Graddoletalli. (Orgs.).Researching Language and Literacy in Social Context. Clevedon, UK: Multilingual Matters, pp. 131-150.

MEHAN, Hugh. (1979). Learning Lessons: Social Organization in the Classroom. Cambridge, MA: Harvard University Press.

MERCADO, Ruth. (1994). Saberes e Social Voices in Teaching. In Amelia Alvarez and Pablo Del Río (Orgs.). Education as Cultural Construction. Madrid: Fundación Infancia y Aprendizaje, pp. 45-53.

MERCER, Neil. (1995). The Guided Construction of Knowledge: Talk amongst Teachers and Learners. Clevedon, UK: Multilingual Matters.

O’CONNOR, Mary Catherine; MICHAELS, Sarah. (1996). Shifting Participant Frameworks: Orchestrating Thinking Practices in Group Discussion.In: Discourse, Learning and Schooling. Debora Hicks, ed. Cambridge: Cambridge University Press, pp. $63-$ 103.

ROCKWELL, Elsie. (1992 ). Tales from Xaltipan: Documenting Literacy and Orality in Rural Mexico. Cultural Dynamics5 (2) 156-175.

(1995 ). En torno al texto: tradiciones docentes y prácticas cotidianas. In: ElsieRockwell (Org.) La escuela cotidiana. Mexico City: Fondo de Cultura Económica, pp. 198-222.

. (1996 ). Keys to appropriation: Rural Schools in Mexico. In: Bradley Levinson etalli (Orgs.). The Cultural Production of the Educated Person. Albany: State University of New York Press. Pp. 301-324.

SCHNEUWLY, Bernard. (1994). Tools to Master Writing: Historical Glimpses. In: James Wertsch and Juan Daniel Ramirez (Orgs.) Literacy and Other Forms of Mediated Action. Madrid: Fundación Infancia y Aprendizaje. Pp. 137-146.

SINCLAIR, John; COULTHARD, Malcolm. (1975). Toward an Analysis of Discourse: The English Used by Teachers and Pupils. Oxford: Oxford University Press.

SWALES, John M. (1990 ). Genre Analysis: English in Academic and Research Settings. Cambridge: Cambridge University Press.

WELLS, Gordon. (1993). Reeevaluating the IRF Sequence: a Proposal for the Articulation of Theories of Activity and Discourse for the Analysis of Teaching and Learning in the Classroom. Linguistics and Education 5: 1-37. 
WERTSCH, James. (1991). Voices of the Mind: a Sociocultural Approach to Mediated Action. Cambridge, MA: Harvard University Press.

Recebido: 04/01/2012

Aceito: 05/10/2012 
